\title{
Níveis de Energia em Dietas para Ovinos Santa Inês: Desempenho ${ }^{1}$
}

\section{Kaliandra Souza Alves ${ }^{2}$, Francisco Fernando Ramos de Carvalho ${ }^{3}$, Antônia Sherlânea Chaves Véras ${ }^{3}$, Marcelo Ferreira de Andrade ${ }^{3}$, Roberto Germano Costa ${ }^{4}$, Ângela Maria Vieira Batista ${ }^{3}$, Ariosvaldo Nunes de Medeiros ${ }^{4}$, Rinaldo José de Souto Maior Junior ${ }^{5}$, Dulciene Karla Bezerra de Andrade ${ }^{6}$}

\begin{abstract}
RESUMO - Os consumos de matéria seca (CMS), energia metabolizável (CEM), extrato etéreo (CEE), proteína bruta (CPB), fibra em detergente neutro (CFDN), fibra em detergente ácido (CFDA) e matéria orgânica (CMO) e o ganho em peso diário (GPD), expressos em kg/dia, e a conversão alimentar (CA) foram determinados para avaliar o efeito de três níveis de energia em dietas para ovinos. Utilizaram-se 18 ovinos da raça Santa Inês, machos não-castrados, com idade média de seis meses e peso vivo médio de $20 \mathrm{~kg}$, alimentados com dietas contendo 2,42; 2,66; e 2,83 Mcal de energia metabolizável (EM)/kg de matéria seca (MS), distribuídos em delineamento em blocos casualizados, com seis repetições. Os CMS, em kg/dia, \%PV e g/kg 0,75 , não foram influenciados pelos níveis de energia na dieta, com médias de 0,88 kg, 3,33\% e 75,52 g, respectivamente. Para CFDN e CFDA houve efeito linear decrescente com o aumento dos níveis de energia na dieta. CEE e CEM, por sua vez, cresceram linearmente com o aumento nos níveis de energia da dieta. Quanto ao CPB, não foi observado efeito significativo com incremento energético. Os níveis de energia da dieta não influenciaram o ganho em peso e a conversão alimentar, que foram de 0,$123 ; 0,137$; e $0,191 \mathrm{~kg}$ e 9,$6 ; 8,4$; e 7,0 , respectivamente.
\end{abstract}

Palavras-chave: consumo, ganho em peso, nutrientes

\section{Dietary Levels of Energy for Santa Inês Sheep: Performance}

\begin{abstract}
The intakes of dry matter (IDM), metabolizable energy (IME), ether extract (IEE), crude protein (ICP), neutral detergent fiber (INDF), acid detergent fiber (IADF) and organic matter (IOM) and the daily weight gain (WG), in kg/day, and feed conversion (FC) were determined to evaluate the effect of three dietary energy levels, for sheep. Eighteen Santa Inês sheep (averaging live weight of $20 \mathrm{~kg}$ six months old) were full fed diets with 2.42, 2.66 and 2.83 Mcal of metabolizable energy (ME)/kg of dry matter (DM). A randomized block design, with six replicates, was used. IDM, in $\mathrm{kg} / \mathrm{day}, \% \mathrm{LW}, \mathrm{g} / \mathrm{kg}^{0.75}$, showed no effect, as the dietary energy levels increased, with average of $0.88 \mathrm{~kg}, 3.33 \%$ and $75.52 \mathrm{~g}$, respectively. INDF and IADF showed linear decreasing effect, as the dietary energy levels increased. IEE and IME increased linearly, as the dietary energy levels increased. There was no significant effect for ICP, as the dietary energy levels increased. Dietary energy levels did not influence weight gain and feed conversion, that were of $0.123,0.137$, and $0.191 \mathrm{~kg}$ and $9.6,8.4$, and 7.0 , respectively.
\end{abstract}

Key Words: intake, weight gain, nutrients

\section{Introdução}

A alimentação é um dos principais componentes, constituindo um fator fortemente restritivo na produção de carne ovina, no nordeste do Brasil. Sua crescente procura requer melhorias nos desempenhos produtivos do rebanho, exigindo, dessa forma, estudos que possibilitem estabelecer quantidades de energia que atendam às necessidades desses animais, observando o tipo de alimento empregado, pois o melhor desempenho de ovinos depende das características do animal e da elaboração de dietas mais eficientes.
Os ruminantes, como outras espécies, procuram ajustar o consumo alimentar às necessidades nutricionais, especialmente em energia.

$\mathrm{O}$ termo freqüentemente empregado para descrever o limite máximo de apetite é o consumo voluntário, adquirido quando o alimento é oferecido à vontade. As estimativas do consumo de alimentos em ovinos são vitais para predição do ganho em peso, e o estabelecimento dos requerimentos nutricionais dos animais, necessários à formulação das dietas (NRC, 1985). Na estimativa do consumo, devem ser consideradas as limitações relativas ao animal, ao alimento

\footnotetext{
${ }^{1}$ Parte da dissertação apresentada pelo primeiro autor à Universidade Federal Rural de Pernambuco.

2 Doutoranda em Zootecnia / Bolsista do CNPq. E.mail: kally alves@hotmail.com

3 Professor do DZ/UFRPE. E.mail: ffrcarva@ufrpe; ferreira@ufrpe; sherlanea@ig.com.br; abatista@ufrpe.br

4 Professor do DAP/CCA/UFPB. E.mail: medeiros@cca.ufpb; rgermano@cft.ufpb.br

${ }^{5}$ Aluno de graduação Zootecnia - UFRPE.
} 
e às condições de alimentação (Burgerm et al., 2000). De acordo com Mertens (1992), o consumo é função do alimento (densidade energética, teor de nutrientes, necessidade de mastigação, capacidade de enchimento, entre outros); do animal (peso vivo, variação do peso vivo, estado fisiológico, nível de produção etc), e das condições de alimentação (espaço no cocho, disponibilidade de alimento, tempo de acesso ao alimento, frequiência de alimentação, entre outros).

As dietas à base de volumosos, caracterizadas pela elevada proporção de fibra, influenciam o consumo pelas características peculiares do trato digestivo dos ruminantes, com longos períodos de permanência do alimento e grande capacidade física de armazenamento do pré-estômago, sendo o mecanismo que regula o consumo, a distensão ruminal, influenciado pelas taxas de digestão e de passagem do alimento (Forbes, 1995).

O teor energético das rações também tem grande influência sobre o desempenho dos animais, pois, o animal consome alimento para manter a ingestão constante de energia em que, o fator determinante da saciedade, nesse caso, é a densidade calórica da ração (Van Soest, 1965).

Mahgoub et al. (2000), avaliando três níveis de energia, baixo, médio e alto $(2,4 ; 2,5$; e $2,7 \mathrm{Mcal}$ de energia metabolizável $(\mathrm{EM}) / \mathrm{kg}$ de matéria seca [MS]), respectivamente, em cordeiros Omani, encontraram consumo de matéria seca (CMS) aos 80 dias de idade, de 3,12;3,65; e 3,68, expressos em porcentagem do peso vivo (\% PV), com diferença estatística entre os tratamentos; e aos 194 dias de idade consumos de 3,73; 3,55; e 3,71\% PV, sem diferirem estatisticamente entre si. Quando expressos em $\mathrm{g} / \mathrm{kg}^{0,75}$ os consumos foram de 76,45 ; 80,21 e $82,10 \mathrm{~g} / \mathrm{kg}^{0,75}$ aos 80 dias e 90,$36 ; 88,58$ e $97,49 \mathrm{~g} / \mathrm{kg}^{0,75}$, aos 194 dias de confinamento.

Signoretti et al. (1998), alimentando bezerros holandeses com dietas contendo diferentes níveis de volumosos, não encontraram efeito nos consumos de matéria seca (CMS) e de matéria orgânica (CMO) em kg dia, \% PV e g/ $\mathrm{kg}^{0,75}$. Resultados semelhantes foram observados por Cardoso et al. (2000), trabalhando com diferentes níveis de concentrado em dietas de novilhos Limousin x Nelore e Carvalho et al. (1997), avaliando o efeito do aumento da inclusão de concentrado em dietas de zebuínos. Por outro lado, Garcia et al. (2000), em trabalho realizado com cordeiros Texel x Bergamácia, Texel x Santa Inês e Santa Inês puros, terminados em confinamento, cujas dietas continham 2,47; 2,38; e 2,39 $\mathrm{kcal}$ de EM/kg de MS, encontraram valores médios de CMS para os diferentes grupos genéticos de 72; 77; e 79 g/ $/ \mathrm{kg}^{0,75}$, respectivamente, obtendo menor consumo quando os níveis de energia foram mais altos. Também, McLeod \& Baldwin (2000), avaliando dietas com 2,29 e 2,81 Mcal de EM/kg de MS para cordeiros encontraram diferença no consumo de MS, sendo 1,13 e 0,97 kg/ dia, respectivamente.

A exigência de energia para ganho significa a quantidade que deve ser fornecida ao animal para aumento no peso corporal. O NRC (1985) sugere, para um animal de $20 \mathrm{Kg}$ de peso vivo (PV), 2,8 Mcal de EM/300 g de ganho em peso diário, em uma dieta baseada em 85\% concentrado. O AFRC (1993) recomenda para cordeiros machos inteiros de 20 e 30 Kg de PV, valores de 2,65 e 3,73 Mcal EM/dia/300 g de ganho de peso diário, respectivamente.

Pires et al (2000), trabalhando com cordeiros $3 / 4$ Texel + 1/4 Ideal, com $20 \mathrm{~kg}$ de PV e ganho diário de $0,250 \mathrm{~kg}$, encontraram exigências líquidas de energia semelhante ao valor recomendado pelo NRC (1985) e superior ao indicado pelo AFRC (1993). No entanto, Carvalho et al. (1998), em trabalho com cordeiros Texel x Ideal, com $30 \mathrm{Kg}$ de PV e ganho médio diário (GMD) de $200 \mathrm{~g}$, encontraram exigência líquida de energia de machos não-castrados para ganho 13,9\% superior ao valor do NRC (1985) e, 31,6\% superior ao estimado segundo AFRC (1993).

Fernandes et al. (1996), analisando o efeito de dois planos nutricionais sobre o desempenho de cordeiros F1 Santa Inês x Crioula, em confinamento, onde as rações continham 2,54 e 2,62 Mcal de EM/kg de MS, formuladas visando obtenção de ganhos em peso médio de 0,200 e $0,250 \mathrm{~kg} / \mathrm{animal} / \mathrm{dia}$, respectivamente, obtiveram média para ganho de peso diário de 0,128 e $0,156 \mathrm{~kg} /$ dia. Garcia et al. (2000), avaliando dietas que continham 2,47; 2,38 e 2,39 kcal de EM, encontraram valores para ganho em peso de 0,211 ; 0,193 e $0,195 \mathrm{~kg} / \mathrm{animal} / \mathrm{dia}$. Em trabalho semelhante, Mahgoub et al. (2000) observaram dietas contendo 2,4; 2,5 ;e 2,7 Mcal EM/kg de MS para ovinos em crescimento e encontraram ganhos em peso de 0,090 ; 0,$115 ;$ e $0,147 \mathrm{~kg} /$ dia respectivamente. Martins et al. (1999), quando avaliaram o desempenho de cordeiros mestiços Texel em confinamento, alimentados com dois níveis de energia na dieta $(2,17$ e 2,72 Mcal $\mathrm{EM} / \mathrm{kg} \mathrm{MS}$ ) encontraram ganho em peso diário de 0,116 e $0,159 \mathrm{~kg} / \mathrm{dia}$, respectivamente.

Pérez et al. (1998), avaliando dietas com 2,7 Mcal 
EM/kg de MS em ovinos da raça Santa Inês, abatidos com $53,4 \mathrm{~kg}$, encontraram ganho em peso diário de $216 \mathrm{~g}$.

A maximização do uso de concentrado, devido à necessidade de se elevar o teor de energia das dietas, acarreta, geralmente, aumento nos custos de produção e maior possibilidade de ocorrências de distúrbios fisiológicos nos animais, entretanto permite rações com maior concentração de nutrientes, que podem ser recomendadas para animais com alto potencial para ganho em peso.

Neste contexto, o objetivo deste trabalho foi avaliar os consumos de matéria seca (CMS), energia metabolizável (CEM); proteína bruta (CPB); fibras em detergente neutro (CFDN); e ácido (CFDA); matéria orgânica (CMO); ganho em peso diário (GPD); e conversão alimentar (CA), de ovinos da raça Santa Inês, alimentados com dietas contendo diferentes níveis de energia.

\section{Material e Métodos}

Este trabalho foi conduzido em 2001, no Galpão de Desempenho e Digestibilidade do Setor de Caprinoovinocultura do Departamento de Zootecnia da Universidade Federal Rural de Pernambuco - UFRPE, localizada em Recife-PE.

Foram utilizados 18 ovinos Santa Inês, machos não-castrados, em crescimento, com idade média de seis meses e peso vivo médio de $20 \mathrm{~kg}$. Os animais foram alojados individualmente em baias, medindo $1,1 \mathrm{~m} \times 0,55 \mathrm{~m}$, providas de comedouros e bebedouros, onde receberam os tratamentos experimentais, constituídos por feno de capim Tífton-85 (Cynodon dactylon), moído em máquina forrageira com peneira de crivo de $8 \mathrm{~mm}$ e diferentes níveis de concentrado, à base de milho e farelo de soja, resultando em diferentes níveis de energia $(2,42 ; 2,66$; e 2,83 Mcal de energia metabolizável (EM)/kg de matéria seca [MS]). Uma mistura mineral foi acrescentada ao concentrado (Tabelas 1, 2 e 3). A ração de maior nível de EM foi formulada para atender aos requerimentos de ganhos de peso diários médios de $300 \mathrm{~g} /$ animal/dia, segundo o NRC (1985).

A duração do experimento foi definida pelo tempo necessário para que todos os animais, de cada tratamento, alcançassem peso médio de abate estabelecido em $33 \mathrm{~kg}$ de peso vivo (PV). Os animais foram pesados ao início do experimento, ao final do período de adaptação, e a cada 14 dias durante o período experimental. Também ocorreram pesagens intermediárias, quando o PV dos animais se aproximou do peso determinado para abate. Alimentos e sobras foram pesados e registrados diariamente para cálculo de consumo diário e conversão alimentar (CA); bem como amostrados a cada sete dias para serem analisados para matéria seca (MS), nitrogênio total, fibra em detergente ácido (FDA), extrato etéreo (EE), matéria orgânica $(\mathrm{MO})$ e matéria mineral $(\mathrm{MM})$, de acordo com metodologia descrita por Silva (1990), sendo que a proteína bruta (PB) foi obtida pelo produto entre o teor de nitrogênio total e o fator 6,25. As determinações de fibra em detergente neutro

Tabela 1 - Teores de matéria seca (MS), proteína bruta (PB), extrato etéreo (EE), fibras em detergente neutro (FDN) e ácido (FDA), matérias orgânica (MO) e mineral (MM) e energia metabolizável (EM) dos ingredientes das dietas

Table 1 - Contents of dry matter, crude protein (CP), ether extract (EE), neutral detergent fiber (NDF), acid detergent fiber (ADF), organic matter (OM), mineral matter (MM) and metabolizable energy (ME) of the ingredients of the diets

\begin{tabular}{|c|c|c|c|c|c|c|c|c|}
\hline \multirow{4}{*}{$\begin{array}{l}\text { Ingredientes } \\
\text { Ingredients }\end{array}$} & \multirow{4}{*}{$\begin{array}{l}\text { MS } \\
D M \\
(\%)\end{array}$} & \multirow{2}{*}{\multicolumn{6}{|c|}{$\begin{array}{c}\text { Nutrientes (\% da MS) } \\
\text { Nutrients }(\% \text { DM) }\end{array}$}} & \multirow{4}{*}{$\begin{array}{l}\mathrm{EM} \\
M E\end{array}$} \\
\hline & & & & & & & & \\
\hline & & \multirow{2}{*}{$\begin{array}{l}\mathrm{PB} \\
C P\end{array}$} & \multirow{2}{*}{$\begin{array}{l}\mathrm{EE} \\
E E\end{array}$} & \multirow{2}{*}{$\begin{array}{l}\text { FDN } \\
N D F\end{array}$} & \multirow{2}{*}{$\begin{array}{l}\text { FDA } \\
A D F\end{array}$} & \multirow{2}{*}{$\begin{array}{l}\text { MO } \\
O M\end{array}$} & \multirow{2}{*}{$\begin{array}{r}\mathrm{MM} \\
M M\end{array}$} & \\
\hline & & & & & & & & \\
\hline $\begin{array}{l}\text { Milho } \\
\text { Corn }\end{array}$ & 87,62 & 9,73 & 4,66 & 15,76 & 3,18 & 98,54 & 1,45 & $3,15^{*}$ \\
\hline $\begin{array}{l}\text { Farelo de soja } \\
\text { Soybean meal }\end{array}$ & 83,65 & 53,74 & 1,08 & 15,74 & 12,45 & 92,89 & 7,11 & $3,18^{*}$ \\
\hline $\begin{array}{l}\text { Feno de Tifton } \\
\text { Tifton hay }\end{array}$ & 89,00 & 7,38 & 1,45 & 84,91 & 42,22 & 93,30 & 6,69 & 1,88 \\
\hline
\end{tabular}

* (NRC, 1985). 
Tabela 2 - Composição percentual dos ingredientes das dietas

Table 2 - Chemical percentage of the ingredients of the diets

\begin{tabular}{|c|c|c|c|}
\hline \multirow[t]{2}{*}{$\begin{array}{l}\text { Ingredientes (\% MS) } \\
\text { Ingredients }(\% D M)\end{array}$} & \multicolumn{3}{|c|}{$\begin{array}{l}\text { Níveis de energia metabolizável na dieta }(\mathrm{Mcal} / \mathrm{kg} \mathrm{MS}) \\
\text { Level of metabolizable energy of the diet (Mcal/kg DM) }\end{array}$} \\
\hline & 2,42 & 2,66 & 2,83 \\
\hline Milho & 14,15 & 35,08 & 56,41 \\
\hline Corn & & & \\
\hline $\begin{array}{l}\text { Farelo de soja } \\
\text { Soybean meal }\end{array}$ & 23,36 & 22,40 & 21,32 \\
\hline $\begin{array}{l}\text { Feno de tifton } \\
\text { Tifton hay }\end{array}$ & 61,70 & 41,43 & 20,86 \\
\hline $\begin{array}{l}\text { Calcário } \\
\text { Limestone }\end{array}$ & 0,30 & 0,60 & 0,91 \\
\hline $\begin{array}{l}\text { Sal mineral } \\
\text { Mineralized salt }\end{array}$ & 0,49 & 0,49 & 0,50 \\
\hline
\end{tabular}

Tabela 3 - Teores de matéria seca (MS), proteína bruta $(\mathrm{PB})$, extrato etéreo (EE), carboidratos totais (CHOT) e não fibrosos (CNF), fibras em detergente neutro (FDN) e ácido (FDA), matéria mineral (MM) e matéria orgânica (MO) e nutrientes digestíveis totais (NDT) das dietas

Table 3 - Contents of dry matter (DM), cude protein (CP), ether extract (EE), total carbohydrates (TCHO), nonfiber carbohydrates (NFC), neutral detergent fiber (NDF), acid detergent fiber (ADF), mineral matter (MM), organic matter (MO) and total digestible nutrients (TDN) of the diets

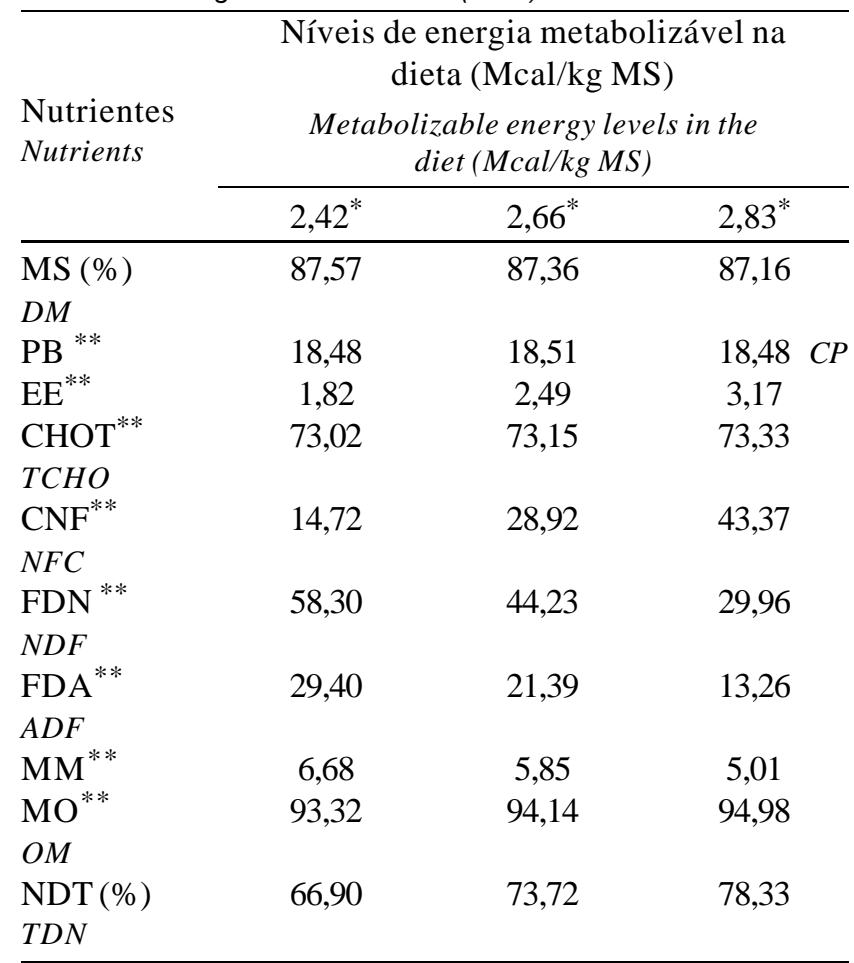

* Obtidos como valor médio de NDT das dietas de seis animais em cada tratamento (Alves, 2002).

* Obtained as average value of dietary TDN of six animals in each treatment (Alves, 2002).

** \% na MS (\% in DM).

R. Bras. Zootec., v.32, n.6, p.1937-1944, 2003 (Supl. 2)
(FDN) foram efetuadas de acordo com metodologia descrita por Van Soest et al. (1991).

As variáveis analisadas foram: consumo de matéria seca (CMS), expresso em quilograma por dia ( $\mathrm{kg} / \mathrm{dia})$, porcentagem do peso vivo e gramas por unidade de tamanho metabólico; consumos de energia metabolizável (CEM), proteína bruta (CPB), fibras em detergente neutro (CFDN) e ácido (CFDA) e matéria orgânica (CMO); ganho em peso diário (GPD), em kg/dia; e conversão alimentar (CA).

$\mathrm{O}$ delineamento experimental utilizado foi em blocos casualizados, com três tratamentos e seis repetições, fazendo-se a interpretação estatística dos resultados por meio de análises de variância e regressão, em função dos níveis de energia na dieta.

Os critérios utilizados para escolha das equações foram o comportamento biológico, coeficiente de determinação $\left(\mathrm{R}^{2}\right)$, que foi calculado como a relação entre a soma de quadrado de regressão e a soma de quadrado total, e a significância, para os parâmetros da regressão, obtida pelo teste $\mathrm{T}$, para os níveis de 1 e $5 \%$ de probabilidade.

\section{Resultados e Discussão}

As médias e os respectivos coeficientes de variação $(\mathrm{CV})$, equações de regressão e coeficiente de determinação $\left(\mathrm{R}^{2}\right)$, referentes aos consumos de nutrientes, ganho em peso diário (GPD) e conversão alimentar (CA), em função dos níveis de energia na dieta, estão apresentados na Tabela 4.

Os consumos de matéria seca (CMS), expressos 
Tabela 4 - Médias, coeficiente de variação (CV), equações de regressão (ER) e coeficiente de determinação $\left(R^{2}\right)$, para os consumos de matéria seca (CMS), matéria orgânica (CMO), energia metabolizável (CEM), proteína bruta (CPB), extrato etéreo (CEE), fibras em detergente neutro (CFDN) e ácido (CFDA), ganho em peso diário (GPD) e conversão alimentar (CA), em função dos níveis de energia metabolizável (EM) das dietas experimentais

Table 4 - Means, coefficient of variation (CV), regression equation (RE) and coefficient of determination $\left(R^{2}\right)$ for intakes of dry matter (IDM), organic matter (IOM), metabolizable energy (IME), crude protein (ICP), ether extract (IEE), neutral (INDF) and acid detergent fiber (IADF), weight gain (WG) and feed conversion (FC), in function of the metabolizable energy levels $(M E)$ in the experimental diets

\begin{tabular}{|c|c|c|c|c|c|c|}
\hline \multirow[t]{2}{*}{$\begin{array}{l}\text { Variáveis } \\
\text { Variable }\end{array}$} & \multicolumn{3}{|c|}{$\begin{array}{c}\text { Níveis EM } \\
\text { (Mcal/kg MS) } \\
\text { ME levels (Mcal/kg DM) }\end{array}$} & \multirow[t]{2}{*}{$\begin{array}{l}\mathrm{CV} \\
(\%)\end{array}$} & \multirow[t]{2}{*}{$\begin{array}{l}\mathrm{ER} \\
R E\end{array}$} & \multirow[t]{2}{*}{$\mathrm{R}^{2}$} \\
\hline & 2,42 & 2,66 & 2,83 & & & \\
\hline $\begin{array}{l}\mathrm{CMS} \text { (kg/dia) } \\
\text { IDM (kg/day) }\end{array}$ & 0,90 & 0,87 & 0,87 & 9,68 & $\mathrm{Y}=0,88$ & \\
\hline $\begin{array}{l}\mathrm{CMS}(\% \mathrm{PV}) \\
I D M(\% L W)\end{array}$ & 3,46 & 3,29 & 3,25 & 10,14 & $\mathrm{Y}=3,33$ & \\
\hline $\begin{array}{l}\text { CMS }\left(\mathrm{g} / \mathrm{kg}^{0,75}\right) \\
I D M\left(g / \mathrm{kg}^{75}\right)\end{array}$ & 78,13 & 74,66 & 73,77 & 9,80 & $\mathrm{Y}=75,52$ & \\
\hline $\begin{array}{l}\mathrm{CMO}(\mathrm{kg} / \mathrm{dia}) \\
\operatorname{IOM}(\mathrm{kg} / \text { day })\end{array}$ & 0,84 & 0,82 & 0,82 & 9,52 & $\mathrm{Y}=0,83$ & \\
\hline $\begin{array}{l}\mathrm{CEM}(\mathrm{Mcal} / \mathrm{kg} \mathrm{MS} / \mathrm{dia}) \\
\operatorname{IME}(\text { Mcal/kg DM/day) }\end{array}$ & 2,18 & 2,33 & 2,45 & 10,9 & $\mathrm{Y}=0,15648+0,82016 \mathrm{EM}^{*}$ & 0,28 \\
\hline $\begin{array}{l}\mathrm{CPB}(\mathrm{kg} / \mathrm{dia}) \\
\text { ICP (kg/day) }\end{array}$ & 0,19 & 0,18 & 0,17 & 10,72 & $\mathrm{Y}=0,18$ & \\
\hline $\begin{array}{l}\mathrm{CEE}(\mathrm{kg} / \mathrm{dia}) \\
I E E(\mathrm{~kg} / \text { day })\end{array}$ & 0,02 & 0,03 & 0,03 & 9,41 & $\mathrm{Y}=-0,02500+0,01893 \mathrm{EM}^{* *}$ & 0,71 \\
\hline $\begin{array}{l}\mathrm{CFDN}(\mathrm{kg} / \mathrm{dia}) \\
I N D F(k g / \text { day })\end{array}$ & 0,47 & 0,33 & 0,21 & 17,92 & $\mathrm{Y}=1,74485-0,53407 \mathrm{EM}^{* *}$ & 0,73 \\
\hline $\begin{array}{l}\text { CFDA (kg/dia) } \\
I A D F(k g / \text { day })\end{array}$ & 0,24 & 0,16 & 0,09 & 19,88 & $\mathrm{Y}=0,95700-0,30177 \mathrm{EM}^{* *}$ & 0,75 \\
\hline $\begin{array}{l}\mathrm{GPD}(\mathrm{kg} / \mathrm{dia}) \\
W G(\mathrm{~kg} / \text { day })\end{array}$ & 0,123 & 0,137 & 0,191 & 29,60 & $\mathrm{Y}=0,15$ & \\
\hline $\begin{array}{l}\text { CA } \\
F C\end{array}$ & 9,6 & 8,4 & 7,0 & 28,18 & $\mathrm{Y}=8,35$ & \\
\hline
\end{tabular}

*, ** Significativo a 5 e $1 \%$ de probabilidade, respectivamente pelo teste $\mathrm{T}$.

*, ${ }^{* *}$ Significant at 5 and $1 \%$ of probability, respectively, by $T$ test.

em quilograma por dia ( $\mathrm{kg} / \mathrm{dia})$, porcentagem do peso vivo (\%PV) e gramas por unidade de tamanho metabólico $\left(\mathrm{g} / \mathrm{kg}^{0,75}\right)$, não foram influenciados pelos níveis de energia na dieta, com médias de $0,88 \mathrm{~kg}, 3,33 \%$; e $75,52 \mathrm{~g}$, respectivamente. Esses consumos médios podem ser considerados relativamente baixos comparados aos preditos pelo NRC (1985), que sugere valores de $1,2 \mathrm{~kg}$ de MS/dia e 6,0\% do peso vivo (PV), para animais de $20 \mathrm{~kg}$ de PV e ganho diários de $300 \mathrm{~g}$ e 2,8 Mcal de energia metabolizável (EM)/kg de matéria seca (MS) na ração, correspondendo à ingestão de 3,36 Mcal EM/dia.

De acordo com Mertens (1994), quando a densidade energética da ração é elevada (baixa concen- tração de fibra em detergente neutro (FDN)), em relação às exigências do animal, o consumo é limitado pela demanda energética, não ocorrendo repleção ruminal. Para rações de densidade energética baixa (teor de FDN elevado), o consumo será limitado pelo enchimento do rúmen-retículo. Dessa forma, provavelmente as dietas experimentais contendo alto teor de $\operatorname{FDN}(58,30 \%)$, conforme tabela relativa à composição bromatológica das dietas, promoveram baixo CMS total, devido à limitação provocada pelo enchimento do rúmen-retículo dos animais. Por outro lado, as dietas que continham altos teores de energia (2,8 Mcal/ kg MS) e baixo nível de fibra (29,96\%), também resultaram em menor consumo total da MS, 
indicando que as exigências energéticas dos animais tenham sido atingidas em níveis mais baixos de consumo; além de possíveis causas da incapacidade do animal de regular o $\mathrm{pH}$ e o meio ambiente ruminal.

Os resultados observados para CMS estão próximos aos encontrados por Mahgoub etal. (2000), quando avaliaram três níveis de energia $(2,4 ; 2,5$ e 2,7 Mcal EM/kg de MS) em cordeiros Omani em crescimento.

Para CMS, o comportamento observado neste estudo foi similar ao encontrado por Signoretti et al. (1998) e Cardoso et al. (2000), trabalhando com diferentes níveis de concentrado em dietas de bovinos. No entanto, os resultados diferiram dos observados por Garcia et al. (2000), quando trabalharam com cordeiros Texel x Bergamácia, Texel x Santa Inês e Santa Inês puros, que encontraram valores para consumo de matéria seca menores quando os níveis de energia foram mais altos; bem como McLeod \& Baldwin (2000), quando avaliaram dois níveis de energia em dietas de cordeiros.

Com base nas considerações de Van Soest (1965), Mertens (1992) e Forbes (1995), possivelmente, o controlador do consumo neste trabalho foi a própria FDN que possui correlação negativa com a densidade energética das dietas.

Para consumo de fibras em detergente neutro (CFDN) e ácido (CFDA) houve efeito linear decrescente com o aumento dos níveis de energia na dieta (Tabela 4), devido à conseqüente redução no teor de FDN na matéria seca total das rações, quando se elevaram os níveis de energia na dieta de acordo com a Tabela 3. Efeito similar foi encontrado por Carvalho et al. (1997), Signoretti et al. (1998), Garcia et al. (2000), Cardoso et al. (2000), Véras et al. (2000), os quais encontraram menores consumos de FDN quando os animais dispunham de níveis mais altos de energia na dieta.

Apresentando comportamento inverso, o consumo de extrato etéreo (CEE) cresceu linearmente $(\mathrm{P}<0,01)$ com o aumento nos níveis de energia da ração (Tabela 4). Esse fato pode ser explicado pelo aumento no teor de extrato etéreo das rações, que foi maior para os tratamentos com maiores percentuais de energia (Tabela 3). Esse efeito corrobora com os encontrados por Carvalho et al. (1997), Signoretti et al. (1998), Cardoso et al. (2000) e Véras et al. (2000).

Similarmente ao CEE, o aumento linear encontrado para consumo de EM pode ser explicado em razão da elevação desses níveis na ração, conforme discuti- do anteriormente. Observa-se, na Tabela 4, que os ovinos consumiram um máximo de 2,45 Mcal/dia, ficando abaixo das recomendações preconizadas pelo NRC (1985) e AFRC (1993) para taxas de ganho em peso de $300 \mathrm{~g} / \mathrm{dia}$, correspondendo a $73 \%$ da recomendação do NRC e $66 \%$ da recomendação do AFRC.

Quanto ao consumo de proteína bruta (CPB), não foi observado efeito significativo do aumento dos níveis energéticos, em função de as dietas serem praticamente isoprotéicas, como pode ser observado na composição bromatológica das dietas.

Para ganho em peso diário (GPD) e conversão alimentar (CA) não houve efeito significativo com o aumento dos teores de energia na dieta, diferindo dos estudos realizados por Mahgoub et al. (2000), quando trabalharam com 2,4;2,5; e 2,7 Mcal EM/kg de MS na dieta, e encontraram valores de 0,09; 0,115; e $0,147 \mathrm{~kg} /$ dia respectivamente; e Garcia et al. (2000), que utilizaram rações com 2,47; 2,38; e 2,39 kcal de EM e obtiveram ganho em peso diário de 211, 193 e $195 \mathrm{~g} /$ dia. Todavia, os resultados observados neste trabalho foram maiores do que os obtidos por Fernandes et al. (1996), avaliando o desempenho de ovinos alimentados com dietas contendo 2,54 e 2,62 Mcal de EM/kg de MS e Martins et al. (1999), que encontraram GPD de 0,116 e $0,159 \mathrm{~kg} /$ dia para os níveis de 2,17 e 2,72 Mcal de EM/kg de MS nas dietas; e menores que os valores observados por Pérez et al (1998), quando trabalharam com 2,7 Mcal $\mathrm{EM} / \mathrm{kg}$ de MS em dietas de ovinos Santa Inês.

O valor de 7,0 observado para CA no nível mais alto de EM é semelhante ao encontrado por Mahgoub et al. (2000), que foi de 7,3 no nível mais alto de energia na dieta e superior ao encontrado por Pérez et al. (1998), de 6,26, quando utilizaram 2,7 Mcal EM/ $\mathrm{kg}$ de MS na dieta de ovinos Santa Inês. Já Garcia et al. (2000) observaram CA de 5,68; 7,12 e 6,31 para níveis de 2,47; 2,38 e 2,39 Mcal de EM, respectivamente; confirmando que o aumento nos níveis de energia da dieta melhora a conversão alimentar.

$\mathrm{Na}$ Tabela 5, pode-se observar o peso inicial, peso de abate e a duração do experimento, em função dos níveis de energia na dieta.

O tempo médio gasto para os animais atingirem peso vivo foi de 97,83; 96,50; e 76,67 dias para os níveis de 2,42; 2,66; e 2,83 Mcal de EM/Kg de MS, respectivamente, o que mostra a influência positiva no nível de energia na dieta em encurtar os dias de confinamento. 
Tabela 5 - Peso inicial (PI), peso de abate (PA) e dias de confinamento (DC), em função dos níveis de energia da dieta

Table 5 - Initial weight (IW), slaughter weight (FW) and feedlot days (FD), according to the dietary metabolizable energy levels (ME)

\begin{tabular}{lccc}
\hline $\begin{array}{l}\text { Variáveis } \\
\text { Variable }\end{array}$ & \multicolumn{3}{c}{$\begin{array}{c}\text { Níveis de EM (Mcal/kg MS) } \\
\text { ME levels }(\text { Mcal/kg DM) }\end{array}$} \\
\cline { 2 - 4 } PI & 2,42 & 2,66 & 2,83 \\
$I W$ & 20,17 & 20,10 & 20,47 \\
PA & & & \\
SW & 31,87 & 31,10 & 31,90 \\
DC & & & \\
$F D$ & 97,83 & 96,50 & 76,67 \\
\hline
\end{tabular}

Tabela 6 - Margem bruta, de acordo com os níveis de inclusão de energia

Table 6 - Gross margin, according to the dietary energy levels

\begin{tabular}{|c|c|c|c|}
\hline \multirow{2}{*}{$\begin{array}{l}\text { Variável } \\
\text { Variable }\end{array}$} & \multicolumn{3}{|c|}{$\begin{array}{c}\text { Níveis de EM (Mcal/kg MS) } \\
\text { ME levels }(\text { Mcal/kg DM) }\end{array}$} \\
\hline & 2,42 & 2,66 & 2,83 \\
\hline $\mathrm{R} \$ / \mathrm{kg} \mathrm{MS}$ & & & \\
\hline$R \$ / \mathrm{kg} D M$ & 0,50 & 0,52 & 0,55 \\
\hline $\mathrm{R} \$$ /animal & & & \\
\hline$R \$ /$ animal & 44,00 & 43,66 & 36,69 \\
\hline $\begin{array}{l}\text { Receita bruta* } \\
\text { Gross revenue* }\end{array}$ & 79,67 & 77,75 & 79,75 \\
\hline $\begin{array}{l}\text { Margem bruta } \\
\text { Gross margin }\end{array}$ & 35,67 & 34,09 & 43,06 \\
\hline
\end{tabular}

* Considerou-se 2,50 R\$, o peso vivo do animal.

* It considered $2.5 R \$$ the alive animal weight.

Na Tabela 6, estão apresentados os valores em reais por $\mathrm{kg}$ de MS consumido e por animal, receita bruta e margem bruta por animal, na qual se observa que o tratamento de maior nível de energia apresentou maior margem bruta, em função de os dias de confinamento terem sido menores, considerando o mesmo custo para mão-de-obra e instalações.

\section{Conclusões}

A utilização de 2,83 Mcal de energia metabolizável por $\mathrm{kg}$ de matéria seca é recomendada por ter proporcionado menor período em confinamento e, conseqüentemente, maior margem bruta.

\section{Literatura Citada}

ALVES, K.S. Níveis de energia em dietas de ovinos Santa Inês: Digestibilidade aparente, desempenho, característica de carcaça e constituintes corporais. Recife: Universidade Federal Rural de Pernambuco, 2002. 80p. Dissertação (Mestrado em Zootecnia) - Universidade Federal Rural de Pernambuco, 2002.

AGRICULTURAL AND FOOD RESEARCH COUNCIL AFRC. Energy and protein requirements of ruminants. $\mathrm{Na}$ advisory manual prepared by the AFRCT Technical Committee on responses to nutrients. Wallingford: $\mathrm{CAB}$ International, 1993. 151p.

BURGER, P.J.; PEREIRA, J.C.; COELHO DA SILVA, J.F. et al. Consumo e digestibilidade aparente total e parcial em bezerros holandezes alimentados com dietas contendo diferentes níveis de concentrado. Revista Brasileira de Zootecnia, v.29, n.1, p.206-214, 2000.

CARDOSO, R.C.; VALADARES FILHO, S.C.; COELHO DA SILVA, J.F. et al. Consumo e digestibilidade aparentes totais e parciais de rações contendo diferentes níveis de concentrado, em novilhos F1 Limousin X Nelore. Revista Brasileira de Zootecnia, v.29, n.6, p.1832-1843, 2000.

CARVALHO, A.U.; VALADARES FILHO, S.C.; COELHO DA SILVA, J.F. et al. Níveis de concentrado em dietas de zebuínos. 1. Consumo e digestibilidade aparente. Revista Brasileira de Zootecnia, v.26, n.5, p.986-995, 1997.

CARVALHO, S.; PIRES, C.C.; PERES, J.R.R. et al. Exigência líquidas de energia para ganho de peso de cordeiros. In: REUNIÃO ANUAL DA SOCIEDADE BRASILEIRA DE ZOOTECNIA, 35., 1998, Botucatu. Anais... Botucatu: Sociedade Brasileira de Zootecnia, 1998, p.104.

FERNANDES, F.D.; BARROS, N.N.; ARAUJO, M.R.A. et al. Efeito de dois planos nutricionais sobre o desempenho de cordeiros F1 Santa Inês x Crioula em confinamento. In: RELATÓRIO TÉCNICO DO CENTRO NACIONAL DE PESQUISA DE CAPRINOS 1987-1995. Sobral: EMBRAPACNPC, 1996. 69-72.

FORBES, J.M. Voluntary food intake and diet selection in farm animals. Wallington: CAB International, 1995. 532p.

GARCIA, I.F.F.; PÉREZ, J.R.O.; TEIXEIRA, J.C. et al. Desempenho de cordeiros Texel x Bergamácia, Texel x Santa Inês e Santa Inês puros terminados em confinamento, alimentados com casca de café como parte da dieta. Revista Brasileira de Zootecnia, v.29, n.2, p.564-572, 2000.

MAHGOUB, O.; LU, C.D.; EARLY, R.J. effects of dietary energy density on feed intake, body weiht gain and carcass chemical composition of Omani growing lambs. Small Ruminant Research, v.37, p.35-42, 2000.

MARTINS, E.N.; MACEDO, F.A.F.; MACEDO, R.M.G. et al. Desempenho e características quantitativas da carcaça de cordeiros mestiços Texel, terminados em confinamento, com diferentes níveis de energia. In: REUNIÃO ANUAL DA SOCIEDADE BRASILEIRA DE ZOOTECNIA, 36., 1999, Porto Alegre. São Anais... Paulo: SBZ/Gmosis, [1999] CDROM.Qualidade de produtos de origem animal. QUA-034.

MCLEOD, K.R.; BALDWIN, R.L. Effects of diet forage:concentrate ratio and metabolizabre energy intake on visceral organ growth and in vitro oxidative capacity of gut tissues in sheep. Journal of Animal Science, v.78, p.760-770, 2000. 
MERTENS, D. R. Analysis of fiber in feeds and its uses in feed evaluation and ration formulation In: SIMPÓSIO INTERNATIONAL DE RUMINANTES, REUNIÃO ANNUAL DA SOCIEDADE BRASILEIRA DE ZOOTECNIA, 29., 1992, Lavras. Anais... Lavras: Sociedade Brasileira de Zootecnia, 1992. p.1-32.

MERTENS, D.R. Regulation of forage intake. In: FAHEY JR., G.C. (Ed.). Forage quality, evaluation and utilization. Madison: American Society of Agronomy, 1994. p.450-493.

NATIONAL RESEARCH COUNCIL - NRC. Nutrient requirements of sheep. 6.ed. Washington, D.C.: National Academy Press, 1985. 99p.

PÉREZ, J.R.O.; GARCIA, I.F.F.; SILVA, R.H. et al. Desempenho de cordeiros Santa Inês Bergamacia alimentados com diferentes níveis de dejetos de suínos. In: REUNIÃO ANUAL DA SOCIEDADE BRASILEIRA DE ZOOTECNIA, 35., 1998, Botucatu. Anais... Botucatu: Sociedade Brasileira de Zootecnia, 1998. p.173.

PIRES, C.C.; SILVA, L.F.; SANCHEZ, L.M.B. Composição Corporal e exigências nutricionais de energia e proteína para cordeiros em crescimentos. Revista Brasileira de Zootecnia, v.29, n.3, p.853-860, 2000.

SIGNORETTI, R.D.; COELHO DA SILVA, J.F.; VALADARES, FILHO, S.C. et al. Consumo e digestibilidade aparente, em bezerros holandeses alimentados com dietas contendo diferentes níveis de volumoso. In: REUNIÃO ANUAL DA SOCIEDADE BRASILEIRA DE ZOOTECNIA, 35, 1998. Botucatu. Anais... Botucatu: Sociedade Brasileira de Zootecnia, 1998. p.422.
SILVA, D.J. Análise de alimentos (Métodos químicos e biológicos). Viçosa, MG: Universidade Federal de Viçosa, 1990. $165 \mathrm{p}$.

Van SOEST, P.J. Symposium on factors influencing the voluntary intake in relation to chemical composition and digestibility. Journal of Animal Science, v.24, n.2, p.834-843, 1965.

Van SOEST, P.J.; ROBERTSON, J.B.; LEWIS, B.A. Methods for extraction fiber, neutral detergent fiber and nonstarch polysaccarides in relation to animal nutrition. Journal of Dairy Science, v.83, n.1, p.3583-3597, 1991.

VÉRAS, A.S.C.; VALADARES FILHO, S.C.; COELHO DA SILVA, J.F. et al. Consumo e digestibilidade aparente em bovinos Nelore, não-castrados, alimentados com rações contendo diferentes níveis de concentrado. Revista Brasileira de Zootecnia, v.29, n.6, p.2151-2156, 2000.

Recebido em: 02/12/01

Aceito em: 14/05/03 